\title{
QUALIDADE DE CEBOLA EM FUNÇÃO DE DOSES DE NITROGÊNIO E ÉPOCAS DE PLANTIO ${ }^{1}$
}

\author{
GARDÊNIA SILVANA DE OLIVEIRA RODRIGUES ${ }^{2 *}$, LEILSON COSTA GRANGEIRO ${ }^{3}$, MARIA ZULEIDE DE \\ NEGREIROS ${ }^{3}$, ANA CLÁUDIA DA SILVA ${ }^{3}$, JOSÉ NOVO JÚNIOR ${ }^{3}$
}

\begin{abstract}
RESUMO - A classificação da cebola realizadas com base no diâmetro dos bulbos e a qualidade medida pelos sólidos solúveis, acidez titulável, a pungência em função de doses de nitrogênio foi avaliada em dois experimentos conduzidos no período de dezembro de 2011 a abril de 2012 e de agosto a dezembro de 2012, na Horta do Departamento de Ciências Vegetais da Universidade Federal Rural do Semi-Árida em Mossoró-RN. O delineamento experimental utilizado foi em blocos casualizados completo com seis tratamentos e quatro repetições. Os tratamentos foram constituídos pelas doses de $\mathrm{N}\left(0,34,67,101,134\right.$ e $\left.168 \mathrm{~kg} \mathrm{ha}^{-1} \mathrm{de} \mathrm{N}\right)$. Cada unidade experimental foi constituída por um canteiro de $3,0 \times 0,8 \mathrm{~m}$, contento oito fileiras de plantas, espaçada de $0,10 \mathrm{x}$ $0,10 \mathrm{~m}$. Utilizou-se, como área útil, as seis fileiras centrais de plantas do canteiro. A aplicação de $101 \mathrm{e} 168 \mathrm{~kg}$ $\mathrm{ha}^{-1}$ de $\mathrm{N}$, favoreceram as maiores percentagem de bulbos de cebola classe 3 , respectivamente nos plantio de dezembro de 2011 e agosto de 2012. A pungência do bulbo aumentou com o fornecimento de nitrogênio até a dose de $93 \mathrm{~kg} \mathrm{ha}^{-1}$, enquanto que, a acidez titulável e os sólidos solúveis reduziram com a aplicação de nitrogênio. O plantio de cebola em agosto de 2012 favoreceu a produção de bulbos de melhor qualidade.
\end{abstract}

Palavras-chaves: Allium cepa. Pungência. Sólidos solúveis.

\section{QUALITY OF ONION DUE TO NITROGEN DOSES AND PLANTING TIMES}

\begin{abstract}
The classification of the onion made based on the diameter of the bulbs and the quality measured by soluble solids, titratable acidity, relation soluble solids /acidity e a pungency due to nitrogen and planting times were evaluated in two experiments conducted from december 2011 to April 2012 and August tha december to 2012, horta in the Department of Plant Sciences Universidade Federal Rural do Semi-Árida em Mossoró-RN. The experimental design was a randomized block with four replications. The treatments consisted of $\mathrm{N}$ rates: $0,34,67,101,134$ and $168 \mathrm{~kg} \mathrm{ha}^{-1} \mathrm{~N}$. Each experimental unit consisted of a bed of 3,0 x $0,8 \mathrm{~m}$, satisfaction eight rows of plants spaced $0.10 \times 0.10 \mathrm{~m}$. Was used as floor area, the six central rows of plants in the flowerbed. The bulb pungency increased with the supply of nitrogen to the dose of $93 \mathrm{~kg} \mathrm{ha}^{-1}$. Acidity and soluble solids reduced with the application of nitrogen. The onion planting in August 2012 favored the production of better quality bulbs.
\end{abstract}

Keywords: Allium cepa. Pungency. Soluble solids.

\footnotetext{
*Autor para correspondência

${ }^{1}$ Recebido para publicação em 06/06/2014; aceito em 04/08/2015.

Trabalho de dissertação do primeiro autor.

${ }^{2}$ Departamento de Ciências Vegetais, UFERSA, Caixa Postal 137, 59625-900, Mossoró-RN; gardeniavg@yahoo.com.br.

${ }^{3}$ Departamento de Ciências Vegetais, UFERSA, Caixa Postal 137, 59625-900, Mossoró-RN; leilson@ufersa.edu.br, zuleide@ufersa.edu.br, ana_claudia33@hotmail.com, agrojunior86@hotmail.com.
} 


\section{INTRODUÇ̃̃̃O}

O consumo da cebola (Allium cepa L.) tem aumentado, tanto na forma in natura como processada, e cada vez mais o mercado consumidor torna-se exigente quanto à obtenção de produtos com qualidade. A qualidade de bulbos está diretamente ligada a aparência externa, tamanho do bulbo, cor, aroma, sabor firmeza e composição química. Tais atributos são determinados, em parte pelo genótipo (FINGER, CASALI, 2002) e influenciados por fatores como manejo cultural, época de plantio, condições climáticas e fertilidade do solo.

$\mathrm{O}$ nitrogénio $(\mathrm{N})$ é o segundo nutriente mais acumulado pela cebola, atrás somente do potássio. Além da fotossíntese, o $\mathrm{N}$ faz parte de outros processos fisiológicos vitais da planta, tais como a absorção de íons, respiração, multiplicação e diferenciação celular (EPSTEIN; BLOOM, 2006). Quando aplicado em doses adequadas favorece o crescimento vegetativo, expande a área fotossinteticamente ativa, e eleva o potencial produtivo (FILGUEIRA, 2000). Em deficiência, as plantas de cebola diminuem o ritmo de crescimento, as folhas ficam com coloração verde pálido, secam e caem precocemente, e os bulbos apresentam-se de tamanho reduzido (RODAS et al., 2005). Já em excesso, pode limitar a produtividade e aumentar as perdas no armazenamento (SOUZA; RESENDE, 2002).

Com relação à resposta da cultura da cebola a adubação nitrogenada, a maior ênfase das pesquisas tem sido nos fatores de produção (RESENDE et al., 2008; VILAS BOAS et al., 2014; RESENDE; COSTA, 2014), entretanto, além dos incrementos na produtividade, o $\mathrm{N}$ também pode influenciar na qualidade do bulbo de cebola. Abdissa et al. (2011) verifica- ram em cebola 'Bombay Red' que a aplicação de $69 \mathrm{~kg} \mathrm{ha}^{-1}$ de $\mathrm{N}$, proporcionou aumento de $24 \%$ na massa média do bulbo, 4\% no índice de colheita e de $17 \%$ na produção de bulbos comercializável em relação ao controle (sem aplicação de N). Com a aplicação de $200 \mathrm{~kg} \mathrm{ha}^{-1}$, Al-Fraihat et al. (2009) obtiveram aumentos nos teores de sólidos solúveis em dois experimentos realizado com a cultivar Giza 20. Morsy et al. (2012) também obtiveram incrementos nos sólidos solúveis e na massa seca de bulbo com a aplicação de nitrogênio. A pungência do bulbo foi afetada pela aplicação de altas doses de nitrogênio (COOLONG; RANDLE, 2003).

Nesse contexto, o presente trabalho teve como objetivo avaliar a qualidade de bulbos de cebola em função de doses de nitrogênio e épocas de plantio.

\section{MATERIAL E MÉTODOS}

A pesquisa constou de dois experimentos, sendo o primeiro conduzido no período de dezembro de 2011 a abril de 2012 e o segundo de agosto a dezembro de 2012, na Horta do Departamento de Ciências Vegetais da Universidade Federal Rural do Semi -Árido em Mossoró-RN, localizada na região noroeste do Estado a $5^{\circ} 12^{\prime}$ ' 26', de latitude sul, $37^{\circ} 19^{\prime}$ 04 ' de longitude à oeste de Greenwich e $18 \mathrm{~m}$ de altitude. $\mathrm{O}$ solo da área experimental foi classificado como Argissolo Vermelho Amarelo Eutrófico, fase caatinga hiperxerófila e relevo plano (EMBRAPA, 2006). Por ocasião da implantação dos experimentos, foram coletadas amostras de solo na profundidade de 0-20 cm para determinação dos atributos químicos (Tabela 1).

Tabela 1. Resultado das análises de solo nas áreas experimentais. Mossoró-RN, UFERSA, 2014.

\begin{tabular}{|c|c|c|c|c|c|c|c|c|c|}
\hline \multirow{2}{*}{$\begin{array}{l}\text { Época de } \\
\text { plantio }\end{array}$} & $\mathrm{pH}$ & $\begin{array}{c}\text { M.O } \\
(\sigma / k \sigma)\end{array}$ & $P$ & K & $\mathrm{Na}$ & $\mathrm{Ca}$ & $\mathrm{Mg}$ & $\mathrm{Al}$ & $\mathrm{H}+\mathrm{Al}$ \\
\hline & & & \multicolumn{3}{|c|}{$\left(\mathrm{mg} \mathrm{dm}^{-3}\right)$} & \multicolumn{4}{|c|}{$\mathrm{cmol}_{\mathrm{c}} \mathrm{dm}^{-3}$} \\
\hline Dezembro/2011 & 7,4 & 5,7 & 24,5 & 172,2 & 10,4 & 2,4 & 0,4 & 0,0 & 0,0 \\
\hline Agosto/2012 & 7,6 & 5,7 & 33,8 & 171,2 & 19,0 & 2,6 & 0,3 & 0,0 & 0,0 \\
\hline
\end{tabular}

O clima local, pela classificação de Köppen, é do tipo BSwh', quente e seco com uma estação chuvosa de janeiro a maio e uma estação seca de junho a dezembro, caracterizado por temperatura média anual de $27,4{ }^{\circ} \mathrm{C}$, precipitação anual de $673 \mathrm{~mm}$ e umidade relativa média de $68,9 \%$ com bioclima tipo 4ath, pela classificação de Gaussen, e índice xerotérmico entre 200 e 150 e seco durante 7 a 8 meses (CARMO FILHO et al., 1991).

As precipitações pluviais e temperaturas médias mensais registradas obtidos na estação meteorológica do Departamento de Ciências Ambientais da UFERSA durante os períodos de condução dos experimentos são mostradas na Tabela 2 .
O delineamento experimental utilizado foi em blocos casualizados completo com seis tratamentos e quatro repetições. Os tratamentos foram constituídos pelas doses de $\mathrm{N}(0,25,50,75,100$ e $125 \%$ da adubação nitrogenada recomendada para cebola por Costa (1998) para o Estado de Pernambuco, correspondendo a uma adubação de $0,34,67,101,134$ e $168 \mathrm{~kg} \mathrm{ha}^{-1}$ de $\mathrm{N}$, respectivamente). Para tanto, foi considerada a soma da adubação de plantio com a adubação de cobertura.

Cada unidade experimental foi constituída por um canteiro de $3,0 \times 0,8 \mathrm{~m}$, contento oito fileiras de plantas, espaçada de $0,10 \times 0,10 \mathrm{~m}$. Utilizou-se como área útil, as seis fileiras centrais de plantas do cantei- 
ro descartando-se as plantas das extremidades.

O preparo do solo constou de aração e gradagem, seguidas do levantamento dos canteiros e adubação de plantio com base na análise do solo e na recomendação de Cavalcanti (1998), sendo aplicado apenas o fósforo, na dose $90 \mathrm{~kg} \mathrm{ha}^{-1}$ de $\mathrm{P}_{2} \mathrm{O}_{5}$ sob a forma de superfosfato triplo.

Tabela 2. Valores médios mensais da temperatura do ar mínima e máxima, umidade relativa do ar (UR) e das precipitações totais nos dois experimentos. Mossoró-RN, UFERSA, 2014.

\begin{tabular}{|c|c|c|c|c|}
\hline \multirow{2}{*}{ Mês } & \multicolumn{2}{|c|}{ Temperatura $\left({ }^{\circ} \mathrm{C}\right)$} & \multirow{2}{*}{$\begin{array}{l}\text { UR } \\
(\%)\end{array}$} & \multirow{2}{*}{$\begin{array}{c}\text { Precipitações } \\
\text { (mm) }\end{array}$} \\
\hline & Mínima & Máxima & & \\
\hline \multicolumn{5}{|c|}{ Experimento 1} \\
\hline Dezembro & 27,44 & 28,55 & 62,74 & 00,00 \\
\hline Janeiro & 26,55 & 27,60 & 62,92 & 28,70 \\
\hline Fevereiro & 26,29 & 27,30 & 67,07 & 47,90 \\
\hline Março & 25,93 & 26,92 & 65,20 & 32,38 \\
\hline Abril & 25,76 & 26,82 & 64,13 & 69,68 \\
\hline \multicolumn{5}{|c|}{ Experimento 2 } \\
\hline Agosto & 26,07 & 27,57 & 55,34 & 0,00 \\
\hline Setembro & 19,44 & 26,64 & 52,48 & 0,00 \\
\hline Outubro & 26,98 & 28,17 & 54,97 & 0,00 \\
\hline Novembro & 27,32 & 28,61 & 59,98 & 0,51 \\
\hline Dezembro & 27,07 & 28,53 & 59,23 & 0,00 \\
\hline
\end{tabular}

A adubação de cobertura foi realizada diariamente via água de irrigação, utilizando-se tanque de derivação produzido com tubo de PVC. As fertirrigações foram iniciadas aos 10 dias após o transplantio (DAT) estendendo-se até os 70 DAT, sendo sua distribuição, ao longo do ciclo, estabelecida a partir da marcha de absorção de nutrientes pela cultura da cebola (Tabela 3), adaptada de Marrocos et al. (2009)

Tabela 3. Distribuição percentual de nitrogênio e potássio ao longo do ciclo da cebola.

\begin{tabular}{ccc}
\hline DAT & $\mathbf{N}(\mathbf{\%})$ & $\mathbf{K}(\mathbf{\%})$ \\
\hline $10-20$ & 9,0 & 9,0 \\
$21-30$ & 15,0 & 15,0 \\
$31-40$ & 25,0 & 20,0 \\
$41-50$ & 35,0 & 30,0 \\
$51-60$ & 10,0 & 20,0 \\
$61-70$ & 6,0 & 6,0 \\
\hline
\end{tabular}

Foram aplicados $135 \mathrm{~kg} \mathrm{ha}^{-1}$ de $\mathrm{K}_{2} \mathrm{O}$ e o nitrogênio de acordo com os tratamentos. As fontes utilizadas foram sulfato de amônio, uréia, nitrato de cálcio e cloreto de potássio. Como fonte de micronutrientes foi aplicado $1 \mathrm{~kg} \mathrm{ha}^{-1}$ do produto comercial Rexolin ${ }^{\circledR}\left(11,6 \%\right.$ de $\mathrm{K}_{2} \mathrm{O}, 1,28 \%$ de $\mathrm{S}, 0,86 \%$ de $\mathrm{Mg}, 2,1 \%$ de $\mathrm{B}, 0,36 \%$ de $\mathrm{Cu}, 2,66 \%$ de $\mathrm{Fe}, 2,48 \%$ de $\mathrm{Mn}, 0,036 \%$ de Mo e 3,38\% de $\mathrm{Zn}$ ), dividido em quatro aplicações quinzenais, a partir dos $30 \mathrm{DAT}$, via fertirrigação.

As mudas foram produzidas em sementeira, com dimensões de $0,80 \mathrm{~m}$ de largura e 0,20 de altura. Utilizaram-se $10 \mathrm{~g} \mathrm{~m}^{-2}$ de sementes para semeadura em sulcos paralelos ao comprimento do canteiro, com profundidade de $1,0 \mathrm{~cm}$ e distância entre sulcos de $0,10 \mathrm{~m}$. O transplantio foi realizado aos 40 dias após a semeadura (DAS), quando as mudas atingiram de 15 a $20 \mathrm{~cm}$ de altura.

A cultivar utilizada foi a Franciscana IPA 11, uma das mais cultivada na região, caracteriza-se por apresentar plantas com folhagem vigorosa, moderadamente ereta, de cor verde escuro e muito cerosa. Os bulbos são de formato globular-alongado, de conformação simétrica, casca fina e coloração amarela intermediária. Em condições de campo, esta cultivar tem apresentado ótimo desempenho agronômico, caracterizando-se ainda por apresentar elevado nível de resistência genética ao mal-de-sete-voltas (Colletotrichum gloeosporioides Penz) e moderada tolerância ao trípes (Thrips tabaci), uma capacidade produtiva superior a $30 \mathrm{t} \mathrm{ha}^{-1}$, com boa conservação pós-colheita. O ciclo, após o transplante, é de, aproximadamente 90 dias.

Visando a prevenção e controle de doenças como mancha púrpura, foram realizadas pulverizações com produtos à base de Mancozeb (Manzate $C$, $2,5 \mathrm{~g} \mathrm{~L}^{-1}$ ) em intervalos de sete dias. O controle de pragas, como tripes e/ou ácaros foi efetuado median- 
te pulverizações alternadas em intervalos de quinze dias com produto a base de Clorfernapir (Pirate $\mathbb{C}$, $0,5 \mathrm{~mL} \mathrm{~L}^{-1}$ ) ou Deltametrina (Decis, $0,3 \mathrm{~mL} \mathrm{~L}^{-1}$ ). $\mathrm{O}$ controle de plantas daninhas foi realizado por capinas manuais com enxada, realizadas sempre que necessário.

A colheita foi realizada em abril/2012 e dezembro/2012 para o transplantio de dezembro/2011 e agosto/2012 respectivamente, quando $70 \%$ das plantas apresentaram-se tombadas. Após a colheita, os bulbos permaneceram no campo por cinco dias, realizando-se o processo de cura ao sol. Em seguida foram levadas ao laboratório do Departamento de Ciências Vegetais da UFERSA, onde permaneceram por cinco dias para completar o processo de cura à sombra. Decorrido o período de cura fez-se a toalete eliminando-se o resto das raízes e parte aérea.

Foi realizada a classificação de bulbos em função do diâmetro transversal, segundo as normas do Ministério da Agricultura e do Abastecimento (BRASIL, 1995) em: Classe 1 (refugo): bulbos com diâmetro < $35 \mathrm{~mm}$; Classe 2: bulbos com diâmetro 35 - $50 \mathrm{~mm}$; Classe 3: bulbos com diâmetro 50 - 75 $\mathrm{mm}$; Classe 4: bulbos com diâmetro 75 - $90 \mathrm{~mm}$; Classe 5: bulbos com diâmetro $>90 \mathrm{~mm}$.

Para as avaliações de sólidos solúveis (SS), acidez titulável (AT) e pungência foram utilizadas seis bulbos por parcela. Para a extração do suco, os bulbos foram triturados em multiprocessador doméstico e filtrados em funil utilizando papel filtro. $\mathrm{O}$ teor de sólidos solúveis ( $\left.{ }^{\circ} \mathrm{Brix}\right)$ foi determinado por refratometria segundo o método da AOAC (2005) por leitura direta em refratômetro digital. Acidez titulável (\% ácido pirúvico) foi obtida utilizando uma alíquota de $20 \mathrm{ml}$ do suco do bulbo, a qual adicionaram -se três gotas de fenolftaleína 1\%. Em seguida realizou-se a titulação até o ponto de viragem com solução de $\mathrm{NaOH}(0,1 \mathrm{~N})$, previamente padronizada. A relação SS/AT determinada pelo quociente entre os atributos sólidos solúveis e acidez titulável de acordo com Chitarra e Chitarra (2005) e a pungência ( $\mu$ mol ácido pirúvico $\mathrm{g}^{-1}$ ) foi obtida através da quantificação de ácido pirúvico, que foi estimada usando o reagente 2,4-dinitrofenilhidrazina (DNPH). A classificação da pungência foi determinada de acordo com o índice indicado pelo "VLI Sweet Index" conforme Vidalialabs (2004) em: "muito suave" (0-2,9 $\mu$ moles $\left.\mathrm{g}^{-1}\right)$, "suave" (3,0-4,2 $\mu$ moles $\left.\mathrm{g}^{-1}\right)$, "levemente pungente" (4,3-5,5 $\mu$ moles $\left.\mathrm{g}^{-1}\right)$, "pungente" (5,6-6,3 $\mu$ moles $\left.\mathrm{g}^{-1}\right)$, "pungência forte" $\left(6,4-6,9 \mu\right.$ moles $\left.\mathrm{g}^{-1}\right)$, "pungência muito forte" (7,0-7,9 $\mu$ moles $\left.\mathrm{g}^{-1}\right)$ e "picante" (8,0-10,0 $\mu$ moles g $\left.{ }^{-1}\right)$.

Análises de variância das características avaliadas foram realizadas isoladamente para cada experimento. Depois procedeu-se à análise conjunta dos experimentos com o auxílio do software SAS. Procedimento de ajustamento de curva resposta em cada característica foi realizado nas doses de nitrogênio usando software Table Curve Package (JANDEL SCIENTIFIC, 1991).

\section{RESULTADOS E DISCUSSÃO}

Houve interação significativa entre as doses de nitrogênio e as épocas de plantio para os bulbos classificados nas classes 2 e 3 (Figuras 1 e 2). Para bulbos pertencentes a classe 1 (Figura 3 ) houve efeito isolado dos fatores doses de $\mathrm{N}$ e época de plantio, enquanto que para o teor de sólidos solúveis apenas foi significativo o fator doses de N (Figura 5), nas demais características nenhum dos fatores foi significativo.

Os bulbos classe 2 (diâmetro 35 a $50 \mathrm{~mm}$ ) foi influenciado significativamente pelas doses de $\mathrm{N}$, e as médias ajustaram-se ao modelo quadrático de regressão no experimento de agosto/2012 (EP2) e para as médias do experimento de dezembro/2011 (EP1) não houve ajustamento a nenhum modelo. Para o plantio na EP2 ocorreu um decréscimo na porcentagem de bulbos classe 2 , à medida que se aumentou as doses de N. O valor máximo estimado foi de 55,5\% no tratamento sem a aplicação de $\mathrm{N}$. Na dose máxima aplicada $\left(168,0 \mathrm{~kg} \mathrm{ha}^{-1}\right.$ de N) o valor foi de apenas $8,8 \%$. Na EP1, embora não tenha ajustado nenhuma equação, observou-se também uma tendência de redução na percentagem de bulbos desta classe, com o aumento da aplicação de $\mathrm{N}$, sendo a maior porcentagem $(62,2 \%)$ obtida na dose de $34 \mathrm{~kg} \mathrm{ha}^{-1} \mathrm{de}$ $\mathrm{N}$ (Figura 1).

Para percentagem de bulbos classe 3 (diâmetro 50 - $75 \mathrm{~mm}$ ) registram-se aumento com doses de $\mathrm{N}$ em forma quadrática nas duas épocas de plantio (Figura 2). As maiores percentagens foram

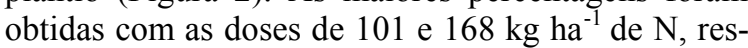
pectivamente para o plantio de dezembro/2011 e agosto/2012, com os respectivos percentuais de 58,84 e $86,42 \%$.

A maior percentagem de bulbos classe 3 obtida no plantio de agosto/2012 em relação a dezembro/2011, deve-se provavelmente as condições climáticas mais propícias no plantio de agosto, principalmente a ausência de chuvas. Na EP1 a quantidade de chuva foi de $178,7 \mathrm{~mm}$, nesse caso, umidade relativa associada as altas temperaturas no período favoreceram o surgimento da doença mancha-púrpura ou queima das pontas (Alternaria porri) e também pode ter comprometido a eficiência da adubação nitrogenada, em função da maior perda do nutriente por lixiviação, diminuindo assim o tamanho do bulbo.

Os resultados obtidos neste trabalho demonstram a importância do $\mathrm{N}$ para o aumento de bulbos comercialmente desejáveis, tendo em vista que essa classe é preferida pelo mercado consumidor e aquela na qual o produtor obtém maior preço. Nasreen et al. (2007) trabalhando com cebola avaliaram o efeito de diferentes doses de $\mathrm{N}\left(0\right.$ a $\left.120 \mathrm{~kg} \mathrm{ha}^{-1}\right)$ e de enxofre (0 a $60 \mathrm{~kg} \mathrm{ha}^{-1}$ ) em diferentes épocas, observaram que o $\mathrm{N}$ teve um efeito significativo sobre a produtividade de cebola em ambos os anos. Resende e Costa (2008) verificaram melhores resultados na produção de cebola com a aplicação de $180 \mathrm{~kg} \mathrm{ha}^{-1}$ de N. Kunz 
et al (2009) trabalhando com adubação nitrogenada em cebola observaram respostas positivas, com a maioria dos bulbos apresentando diâmetros maiores que $55 \mathrm{~mm}$. Resende et al. (2008) observaram que a dose de $153,6 \mathrm{~kg} \mathrm{ha}^{-1}$ de $\mathrm{N}$ promoveu uma percentagem de $85,8 \%$ de bulbos da classe 3 .

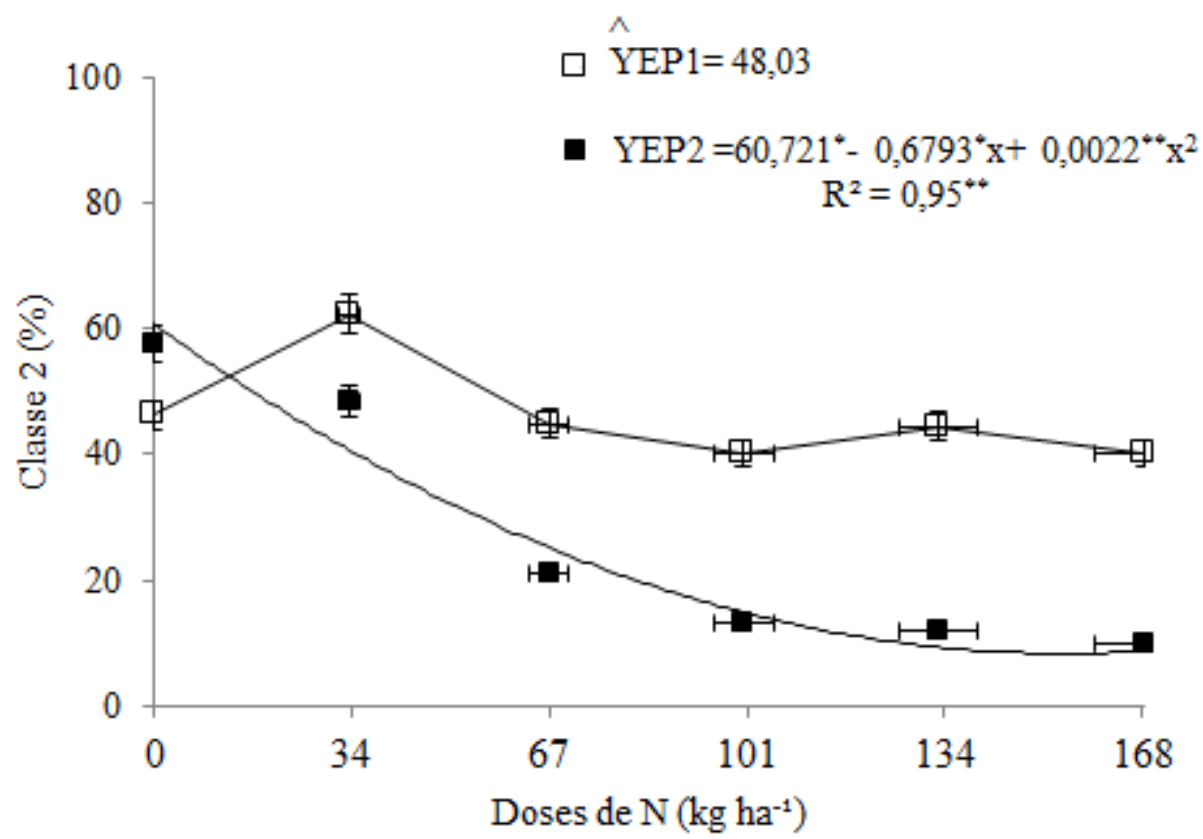

Figura 1. Percentagem de bulbos de cebola classe 2 (diâmetro 35 a $50 \mathrm{~mm}$ ) em função de doses de nitrogênio (N) e épocas de plantio (EP). Mossoró/RN, UFERSA, 2014.

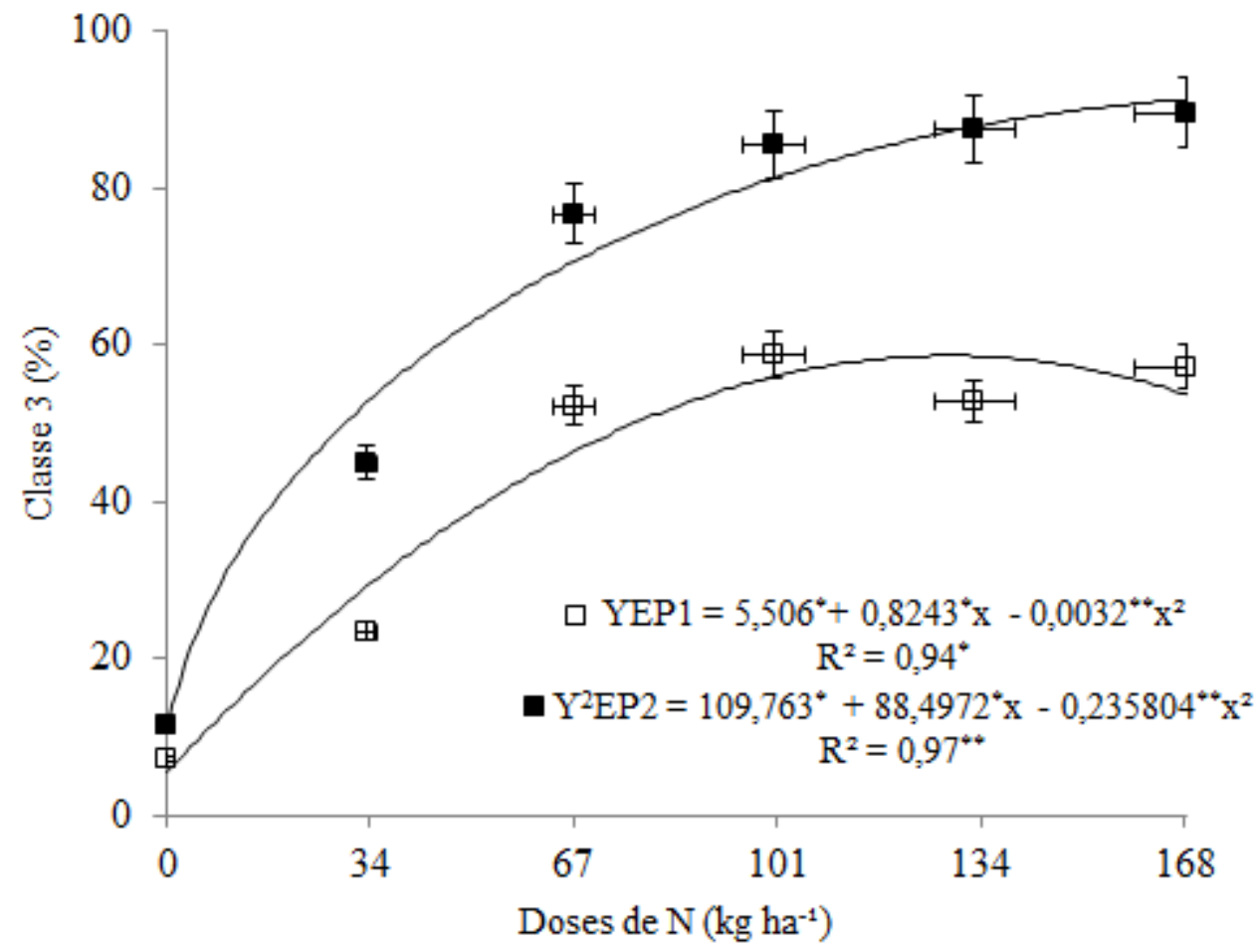

Figura 2. Percentagem de bulbos de cebola classe 3 (diâmetro 75 a $90 \mathrm{~mm}$ ) em função das doses de nitrogênio (N) e épocas de plantio (EP). Mossoró/RN, UFERSA, 2014.

Verificou que para os bulbos classe 1 (diâmetro $<35 \mathrm{~mm}$ ) considerados não comerciais houve uma redução da percentagem de bulbos a me- dida que se aumentou as doses de nitrogênio (N), com o menor valor obtido com aplicação de $168 \mathrm{~kg}$ $\mathrm{ha}^{-1}$ de $\mathrm{N}(0,47 \%)$. A redução em relação ao trata- 
mento sem aplicação de $\mathrm{N}$ foi de 98,8 \% (Figura 3). Cecílio Filho et al. (2010) observaram uma redução na produção de bulbos com diâmetros menores que $35 \mathrm{~mm}$ com a aplicação de nitrogênio e a maior dose aplicada (150 $\left.\mathrm{kg} \mathrm{ha}^{-1} \mathrm{de} \mathrm{N}\right)$ proporcionou um percentual de apenas $0,57 \%$ de bulbos classe 1 , demonstrando que o $\mathrm{N}$ contribui para o aumento da produtividade de bulbos de maior tamanho, resultados semelhantes foram observados por Resende et al. (2008) trabalhando com doses de $\mathrm{K}$ e N, afirmam que o nitrogênio contribuiu para maior produtividade, sobretudo na produção de maior tamanho de bulbo.

Com relação à época, o plantio de dezembro/2011 apresentou uma porcentagem de bulbos classe 1 de $11,53 \%$, enquanto em agosto/2012 a média foi de $6,86 \%$. Conforme discutido anteriormente, as condições mais favoráveis na EP2 proporcionaram a produção de bulbos maiores.

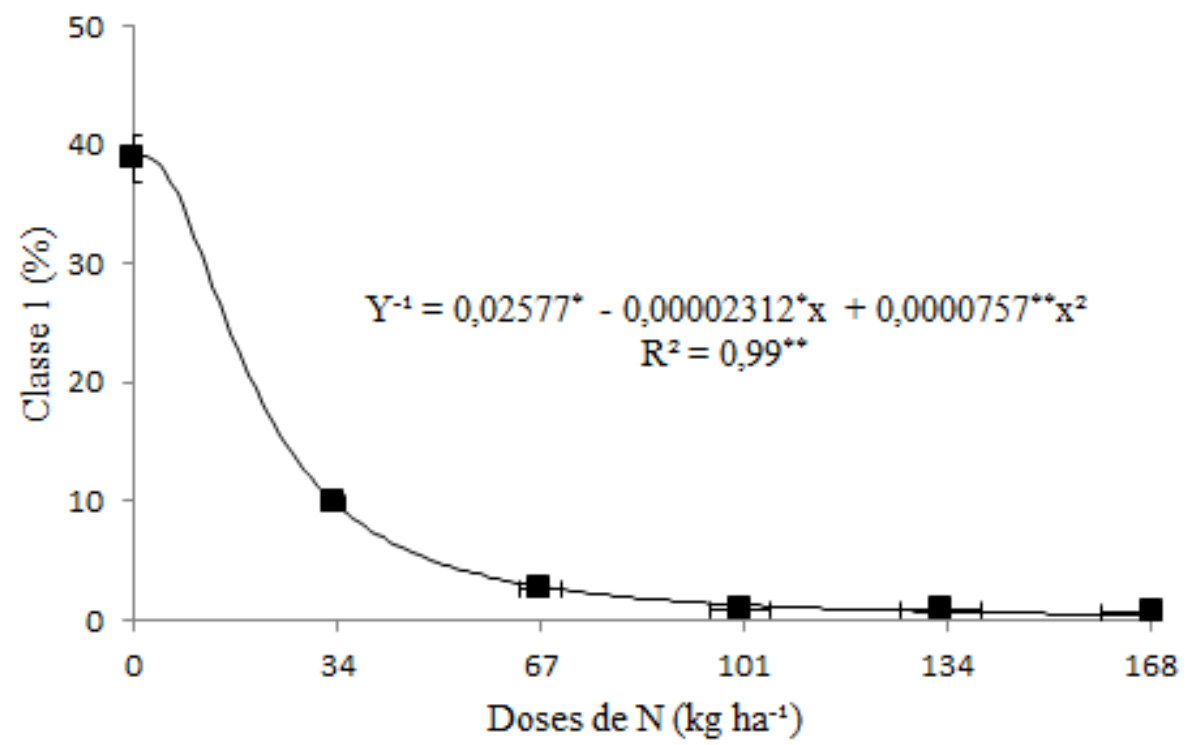

Figura 3. Percentagem de bulbos de cebola classe 1 (diâmetro $<35 \mathrm{~mm}$ ) em função de doses de nitrogênio (N). Mossoró/RN, UFERSA, 2014.

Quanto aos bulbos da classe 4 (diâmetro 75 a $90 \mathrm{~mm}$ ) foi observada apenas no plantio de agosto/2012. Nesta, houve efeito significativo das doses de $\mathrm{N}$, com maior percentual $(4,5 \%)$ alcançado na dose de $168 \mathrm{~kg} \mathrm{ha}^{-1}$ (Figura 4). Bulbos de tamanho muito grande também não são comercialmente desejáveis, obtendo-se preços inferiores aos da classe 3.

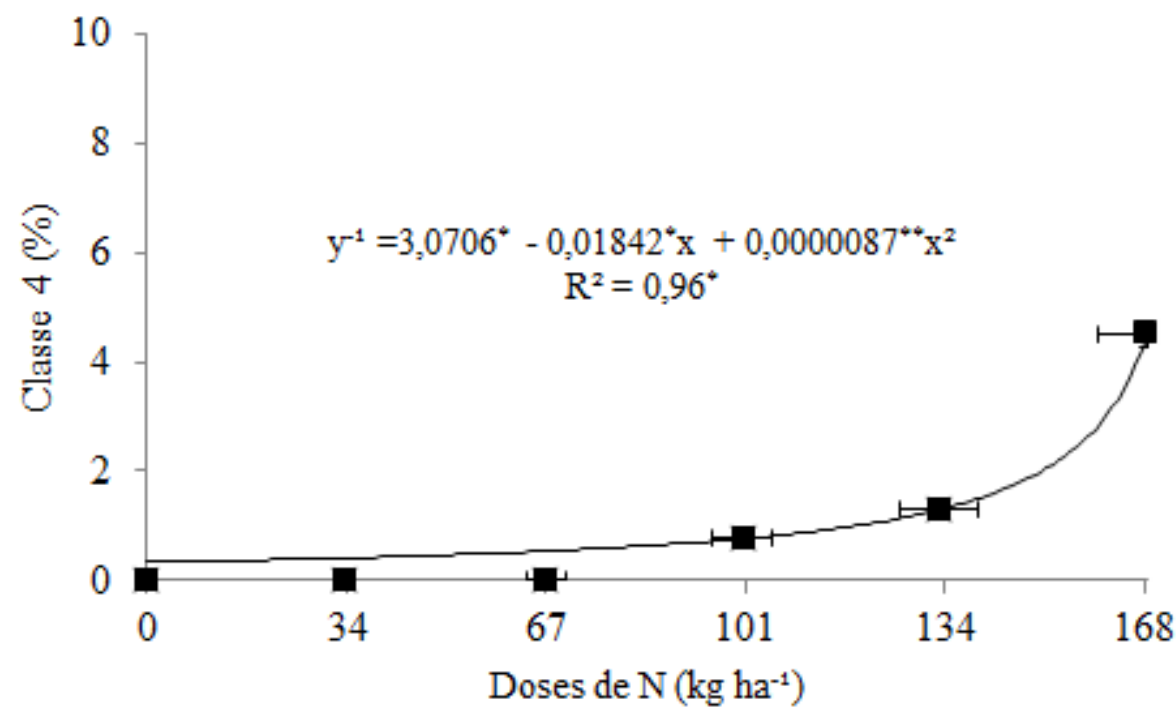

Figura 4. Percentagem de bulbos de cebola classe 4 (diâmetro 75 a $90 \mathrm{~mm}$ ) em função de doses de nitrogênio (N). Mossoró/RN, UFERSA, 2014. 
Os teores de sólidos solúveis diminuíram com o incremento de doses de $\mathrm{N}$, sendo que na ausência da aplicação o valor foi de $9,87^{\circ}$ Brix. O decréscimo estimado foi de $0,7^{\circ}$ Brix entre o tratamento sem aplicação e aquele que proporcionou menor valor de SS $\left(101 \mathrm{~kg} \mathrm{ha}^{-1}\right.$ de $\left.\mathrm{N}\right)$ com a dose máxima de $\mathrm{N}$ aplicada (Figura 5A). Provavelmente, a redução nos SS ocorreu devido ao efeito diluição, pois o aumento de doses de $\mathrm{N}$ favoreceu a produção de bulbos de maior tamanho ocasionando uma diluição dos açúcares. Esses resultados estão de acordo com os de Coolong e Randle (2003) e Bolandadnazar et al. (2012). Entretanto discordam de Morsy et al. (2012) que verificaram aumento dos SS com o aumento dos níveis de N com a cultivar Giza 6 e Randle (2000) não verificou diferença significativa para SS na cultivar Granex 33 .

Os valores de sólidos solúveis obtidos no presente trabalho foram próximos aos encontrados por Grangeiro et al. (2008) que avaliaram 18 cultivares de cebola em Mossoró-RN, entre elas a IPA 11 $\left(10,61^{\circ}\right.$ Brix $)$. Os resultados discordam de

A pungência máxima estimada foi de 5,14

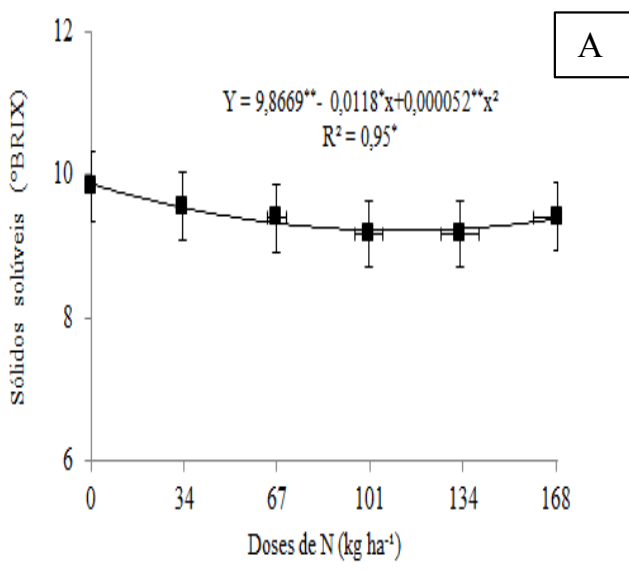

$\mu$ moles ácido pirúvico $\mathrm{mL}^{-1}$ obtida com a aplicação de $93 \mathrm{~kg} \mathrm{ha}^{-1}$ de N (Figura 5B). Esses resultados estão de acordo com os obtidos por Bolandadnazar et al. (2012), que também verificaram aumentos na pungência da cebola com a aplicação de N. De acordo com Randle (1997) e McCallum et al. (2005), a intensidade da pungência é governada por fatores genéticos e ambientais, nesse caso com destaque para o teor de $\mathrm{S}$ e $\mathrm{N}$ no solo, temperatura e disponibilidade de água.

Com base na classificação da pungência proposta por Vidalialabs (2004), os resultados obtidos com a cultivar Franciscana IPA 11 no presente trabalho, classifica-a como levemente pungente. Segundo Souza et al. (2008) existe no mercado uma preferência para o consumo de cebola com pungência de moderada a forte.

Pela análise de regressão houve ajuste significativo de efeito quadrático para acidez e pungência da cebola em função das doses de N. A acidez titulável foi reduzida com o aumento das doses, com máximo obtido $(0,37 \%)$ sem a aplicação N (Figura 5C).

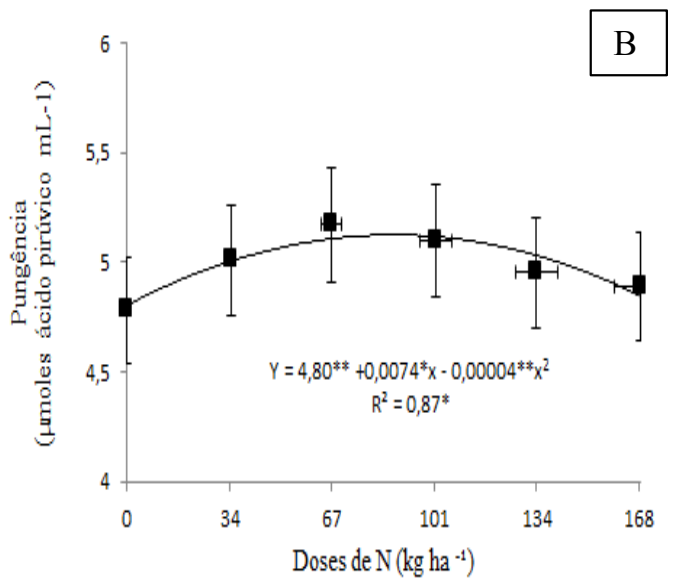

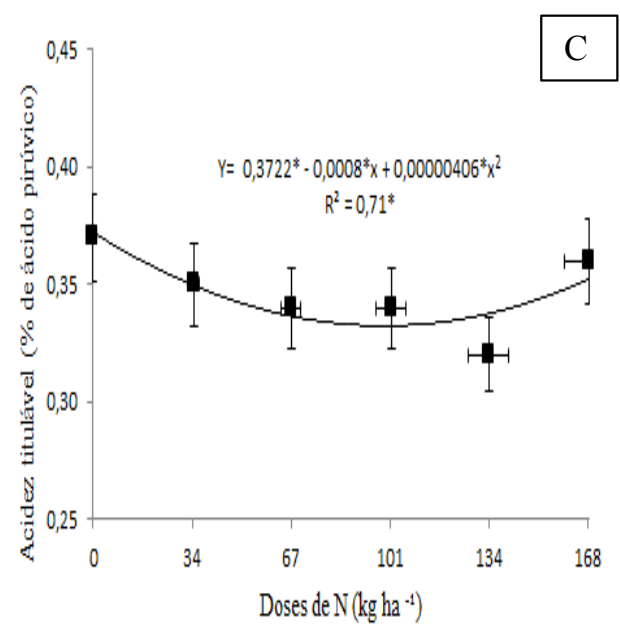

Figura 5. Sólidos solúveis (A), pungência (B) e acidez titulável (C) de cebola em função de doses de nitrogênio (N) Mossoró/RN, UFERSA, 2014. 


\section{CONCLUSÕES}

A aplicação de 101 e $168 \mathrm{~kg} \mathrm{ha}^{-1}$ de N, favoreceram as maiores percentagem de bulbos de cebola classe 3 , respectivamente nos plantio de dezembro de 2011 e agosto de 2012

A pungência do bulbo aumentou com o fornecimento de nitrogênio até a dose de $93 \mathrm{~kg} \mathrm{ha}^{-1}$. Enquanto que, a acidez titulável e os sólidos solúveis reduziram com a aplicação de nitrogênio.

O plantio de cebola em agosto de 2012 favoreceu a produção de bulbos de melhor qualidade.

\section{REFERÊNCIAS}

ABDISSA, Y.; TEKALIGN, T.; PANT, L. M. Growth, bulb yield and quality of onion (Allium cepa L.) as influenced by nitrogen and phosphorus fertilization on vertisol I. growth attributes, biomass production and bulb yield. African Journal of Agricultural Research. v. 6, n. 14, p. 3252-3258. 2011.

AL-FRAIHAT, A. H. Effect of different nitrogen and sulphur fertilizer levels on growth, yield and quality of onion (Allium cepa, 1.). Jordan Journal of Agricultural Sciences. v. 5, n. 2, p. 155-165. 2009.

AOAC. Association of Official Analytical Chemists. 1992. Official methods of analysis. Washington: AOAC. 1114 p.

BOLANDNAZAR, S.; MOLLAVALI, M.; TABATABAEI, S. J. Influence of $\mathrm{NH}_{4} \mathrm{NO}_{3}$ and $\mathrm{K}_{2} \mathrm{SO}_{4}$ on qualitative characteristics of onion. Scientia Horticulturae. v. 136, p. 24-28. 2012.

BRASIL. Ministério da Agricultura, Abastecimento e Reforma Agrária, Portaria n. 529 de 18 ago. 1995. Diário Oficial da República Federativa do Brasil, Brasília, DF, 1 set. 1995. Seção 1, p.135.

CARMO FILHO, F.; ESPÍNOLA SOBRINHO, J.; MAIA NETO, J. M. Dados climatológicos de Mossoró: um município semi-árido nordestino. Mossoró: ESAM, 1991. 121 p. (Coleção Mossoroense, C. 30).

CAVALCANTI F. J. A. (Coord.). 1998. Recomendações de adubação para o Estado de Pernambuco: $2^{\mathrm{a}}$ aproximação. Recife: IPA. 198 p.

CECÍLIO FILHO, A. B. et al. Produtividade e classificação de bulbos de cebola em função da fertilização nitrogenada e potássica, em semeadura direta. Científica, v. 38, n. 1/2, p. 14-22, 2010

CHITARRA, M. I. F.; CHITARRA, A. B. 2005. Pós colheita de frutos e hortaliças: Fisiologia e Manu- seio. Lavras: UFLA, 785 p.

COOLONG, T. W.; RANDLE, W. M. Ammonium nitrate fertility levels influence flavour development in hydroponically grown 'Granex 33' onion. Journal of the Science of Food and Agriculture. v. 83, n. 5 , p. 477-482. 2003.

COSTA, C. P. Tendências da Cebolicultura Mundial para o Próximo Milênio. Informativo da Associação Nacional dos Produtores de cebola - ANACE, n 3. Fevereiro de 1998.

EMPRESA BRASILEIRA DE PESQUISA AGROPECUÁRIA. - Brasília, DF : Embrapa Informação Tecnológica, 2006.

FILGUEIRA, F. A. R. Manual de Olericultura: Agrotecnologia moderna na produção e comercialização de hortaliças. Viçosa, 2000. 402 p.

FINGER F. L; CASALI V. W. D. Colheita, cura e armazenamento da cebola. Informe Agropecuário. v. 23, p. 93-98. 2002.

GRANGEIRO, L. C. et al. Características qualitativas de genótipos de cebola. Revista Ciência e Agrotecnologia. v. 32, n. 4, p. 1087-1091, 2008.

JANDEL SCIENTIFIC. Table Curve: curve fitting software. Corte Madera, CA: Jandel Scientific, 1991. $280 \mathrm{p}$.

KUNZ, V. L. et al. Produtividade de cebola sob diferentes fontes e modos de aplicação de adubos nitrogenados em cobertura. Revista biodiversidade, v. 8 , n. 1, p. 31-37. 2009

LOPES, A.S. Manual de fertilidade do solo. São Paulo: ANDA/POTAFOS, 1989. 153 p.

Mc CALLUM, J. et al. Sulfur and nitrogen fertility affects flavour of field-grown onions. Plant Soil, v. 269, n. 1, p. 151-158. 2005.

MALAVOLTA, E. Manual de nutrição mineral de plantas. São Paulo: Agronômica ceres, 2006. 638 p.

MAY, A. et al. Produtividade de híbridos de cebola em função da população de plantas e da fertilização nitrogenada e potássica. Horticultura Brasileira, v. 25 , n. 1 , p. 53-59. 2007.

MARROCOS, S. T. P. et al. Crescimento e acúmulo de nutrientes em cebola IPA 11. Horticultura Brasileira, v. 27, p. 627-631. 2009.

MOHANTY B. K; DAS J. N. Response of rabi onion cv. Nasik Red to nitrogen and potassium fertilization. Vegetable Science, v. 28, n. 1, p. 40-42. 2001. 
MORSY, M. G. et al. Productivity and storability of onion as influenced by the different levels of NPK fertilization. Journal of Agricultural Research, v. 38 , n. 1 , p. $171-187.2012$.

MOZUMDER, S. N.; MONTRUZZAMAN, M.; HALIM, G. M. A. Effect of N, K and S on trhe yield and storability of transplanted onion (Allium cepa $\mathrm{L}$.) in the Hilly Region. Journal of Agriculture and Rural Development, v. 5, n. 1, p. 58-63. 2007.

NASREEN, S. et al. Nutrient uptake and yield of onion as influenced by nitrogen and sulphur fertilization. Bangladesh Journal of Agricultural Research, v. 32, n. 3, p. 413-420. 2007.

RANDLE, W. M. Onion flavor chemistry and factors influencing flavor intensity. ACS symposium series. v. 660, p. 41-42. 1997.

RANDLE, W. M. Icreasing nitrogen concentration in hydroponic solutions affects onion flavor and bul quality. Journal of the American Society for Horticultural Science, v. 125, n. 2, p. 254-259. 2000.

RESENDE, G. M.; COSTA, N. D. Épocas de plantio e doses de nitrogênio e potássio na produtividade e armazenamento da cebola. Pesquisa Agropecuária Brasileira, v.4 3, n. 2, p. 221-226. 2008.

RESENDE G. M; COSTA N. D; PINTO J. M. Produtividade e qualidade pós-colheita de cebola adubada com doses crescentes de nitrogênio e potássio. Horticultura Brasileira, v. 26, n. 3, p. 388-392. 2008.

RESENDE, G. M. de; COSTA, N. D. Effects of levels of potassium and nitrogen on yields and postharvest conservation of onions in winter. Revista Ceres, v. 61, n. 4, p. 572-577. 2014

RODAS, C. L. et al. Influência da adubação nitrogenada na cultura da cebola em dois sistemas de cultivo. In: Congresso brasileiro de olericultura. Resumos... Horticultura Brasileira. Disponível em: $<$ abhorticultura.com.br/eventosx/trabalhos/>, 2005.

SOUZA J. O. et al. Avaliação de genótipos de cebola no semi-árido Nordestino. Horticultura Brasileira, v. 26 , n. 1, p. 97-101. 2008

SOUZA, R. J. de; RESENDE, G. M. de. Cultura da cebola. Lavras: UFLA/ FAEPE, 2002. 115 p. Textos acadêmicos.

VIDALIALABS - VLI Sweet index (Sweetometer). 2004. Disponível em http://www.vidalialabs.com/ images/sweetometer.jpg/ Acesso em: nov. 2013.
VILAS BOAS, R. C. et al. Rendimento da cultura da cebola submetida a níveis de água e nitrogênio por gotejamento. Semina, v. 35, n. 2, p. 633-646. 2014. 